\title{
Reported Impacts of Interior Plantscaping in Office Environments in the United States
}

Caroline H . Pearson-M ims ${ }^{1}$ and Virginia I. Lohr ${ }^{2}$

\begin{abstract}
ADDITIONAL INDEX WORDS. benefits of plants, emotional responses, foliage plants, human-horticulture relationships, human issues in horticulture, human well-being, interior landscaping, people-plant interactions, room assessment, workplace

SummaRY. Interiorscaping has been prevalent in office environments in the $U$ nited States since the 1960s. H istorically, proponents of interior plantings have cited numerous benefits, including improved employee morale, increased productivity, and reduced absenteeism when plants are added to the workplace, despite little scientific research to support these claims. Contemporary research is beginning to document some of these purported benefits of interior plantings on human comfort, well-being, and productivity. If researchers continue to provide concrete evidence that interaction with plants is directly linked to improved human health and well-being, this information will provide further justification for the use of interior plants in a variety of indoor work settings. With an ever-increasing emphasis by business managers on minimizing costs, it is important for industry professionals to provide quantifiable justification for the inclusion of plants in modern work environments.
\end{abstract}

M

ost people intuitively feel that contact with plants and nature is restorative to the human spirit (Fisher, 1990; Lewis, $1979,1996)$. This common belief in the positive effects of plants on people is evidenced by the widespread use of interior plantscaping in office environments, particularly in those of large businesses (Lewis, 1979; M archant, 1982; Scrivens, 1980; Shoemaker et al., 1992; Snyder, 1995).

Interior planting has been prevalent in these work settings since the 1960s, when the "office landscape," characterized by the abundant use of large, potted plants to separate workspaces, became popular in the U nited States (Snyder, 1995; Sundstrom, 1986). Since then, corporate managers, interior designers, and horticulturists have promoted the practice (C onklin, 1972, 1978; Jaeger, 1969; M archant, 1982; Rodgers; 1968; Scrivens, 1980; Snyder, 1995; Tresch, 1971; Zanardelli, 1969).

D epartment of H orticulture and L andscape Architecture, Washington State U niversity, Pullman, WA 99164-6414. The cost of publishing this paper was defrayed in part by the payment of page charges. U nder postal regulations, thispaper therefore must be hereby marked advertisement solely to indicate this fact.

${ }^{1}$ Research technologist.

2professor. 
They have claimed, for example, that employeemorale, productivity, and efficiency are improved, and absenteeism is reduced, when plants are present in the workplace, despitescant scientific research to support these claims. Some of these proponents cite case studies using self-reported ratings by employees and supervisors as justification for interior plantings. They believe that plants create a more pleasant working environment, thereby promoting the conditions for improved worker productivity. Compared to the costs of employee salaries and benefits, interior landscaping appears to be an economical company expenditure and a prudent investment in both the company and its employees (Snyder, 1995).

What are the origins of interior plantscaping in the workplaceand what evidence is there to support the positive claims regarding the impact of these interiorscapes? A glimpse into the history of thispracticeand the research that has been conducted may help explain its predominance and also provide direction for further scientific research. With an ever-increasing emphasis by business managers on minimizing costs, it is important for industry professionals to beableto provide quantifiable justification for the inclusion of plants in modern work environments.

\section{History of the office landscape}

During the late 1950s, the office landscape, or Burolandschaft, approach to office planning was developed and widely implemented in West Germany (Pile, 1976, 1977, 1978; Rodgers, 1968; Snyder, 1995). The concept was developed by the Quickborner Team for Planning and O rganization, a group of management consultants and designers who specialized in office organization (Pile, 1976, 1977, 1978). They believed that the physical design of the office environment played a significant role in work processes, and that efficiency and productivity could be maximized by enhancing communication among employees (H oward, 1972; Pile, 1976, 1978). They studied interaction among individuals in an organization over time and used actual communication patterns for planning the physical space (Pile, 1976, 1977, 1978). O ne of their primary goal swasto create a pleasant workplace that provided visual and physical comfort through the use of interior plants (D uffy, 1969; Snyder,
1995). To this end, the Q uickborner Team developed a set of 68 rules for developing an office landscape (Pile, 1978).

In the characteristic Q uickborner design, large foliage plantswere densely installed to screen work areas, define circulation routes, and separate workstations (Pile, 1978; Rodgers, 1968; Snyder, 1995). The plants softened the atmosphere of the office, introduced natural elements to an otherwise stark environment, gave more privacy to the worker, and served an acoustical purpose, aswell (Boje, 1971; J aeger, 1969; Pile, 1976, 1978; Rodgers, 1968; Snyder, 1995). The ability of the plants to improve air quality by absorbing carbon dioxide was noted as an additional benefit (Boje, 1971).

The landscaped office was unique among office designs of the time. It was an "open" office, with irregularly clustered workspaces separated by plants and employees grouped according to their work relationshipsand needs, rather than by formal patterns established by organizational charts (Pile, 1978). U nlike the traditional office, typified by its linear layout, there were no stationary partitions, walls, or private offices to inhibit communication among workers (D uffy, 1969; Pile, 1976, 1978). O ffice landscape proponents were critical of conventional offices, because they believed that these designs inhibited productivity and creative interaction (Pile, 1976, 1978).

In the conventional office, an employee'sstatus, or rank, wasextremely important. It wascustomary for managers and supervisors to be rewarded for their accomplishments with private offices (Pile, 1977, 1978). The Q uickborner team believed that worker preoccupation with status could interfere with efficiency, because employees would concentrate more time on office politics and obtaining a private workspace than on working productively (Pile, 1978). They believed that eliminating private offices through use of the office landscape design would alleviate this problem.

Accounts of office landscapes in Germany reported improved employee morale, job satisfaction, and efficiency, and decreased absenteeism when plants were present compared to conventional, unplanted offices(Boje, 1971; C onklin, 1972, 1978; D uffy, 1969; Pile, 1976). In one survey of $1,220 \mathrm{German}$ office workers, while a majority reported that their attitudes toward work, their output, and the numbers of errors that they made were unchanged from previous office settings, they also responded that thelandscaped officeswere " pleasant to livein" and that therewere "justenough (plants) to make the office pleasant" (Boje, 1971).

O ffice landscapes soon began to appear in other areas across Europe, particularly in the Scandinavian countries and England (Pile, 1976). Reports from these office landscapes also were promising.

\section{Major test cases of office landscaping in the United States}

O ffice landscaping based on the Q uickborner model began to appear in the U nited States in the early 1960's. It initially was received with skepticism, because it differed quite radically from predominant office designs of the time and many planners considered its rules too restrictive (Pile, 1976, 1978).

D uring 1967-71, manylargecompanies in the U nited States, principally those with international operationsthat knew firsthand of the European studies, began to experiment with office landscapes (J aeger, 1969; Pile, 1976, 1978; Rodgers, 1968). The first experiment was built in 1967 for DuPont in Wilmington, Del. (Pile, 1977, 1978). This test space occupied one floor of an office building; the remaining floors contained conventional offices. Employee reactions to the trial were generally positive, praising its improved flexibility, reduced renovation and installation costs, and increased office efficiency (J aeger, 1969; Rodgers, 1968). H owever, many senior employees, who had forfeited their privateoffices, complained of alack of privacy (Pile, 1978). D uPont did not adopt the office landscape permanently and eventually moved the experimental group into conventional offices (Pile, 1977). Similar cost and operational efficiencies were noted that sameyear during a comprehensiveevaluation of office landscaping at the U .S. Department of Labor in Washington, D.C. (Pile, 1977).

In 1968, more major office landscape studies were conducted. T wo of the most important were those conducted for the Port Authority of $\mathrm{N}$ ew Yorkand forE astman Kodak (Pile, 1976, 1978). Employees in both tests reacted positively toward the appearance of the 
new designs, and improved communication and interaction were reported. For thePortAuthority, installation costs were reduced by approximately $60 \%$ and moving costswerereduced byabout $97 \%$ compared to the traditional office. For both studies, thereweresome problems. At the Port Authority, there was no increase in worker efficiency, productivity, or attitudes toward work (H oward, 1972; Pile, 1976). At Kodak, there were negative responses related to privacy issues, similar to those that surfaced in the earlier D uPont study. The overall employeeresponseto thesestudies was, however, quite favorable, and both organizations widely integrated office landscaping in their workplaces (Pile, 1976).

For the next several years, office landscape test installations continued, often with mixed results. At M ontgomery Ward's headquarters in Chicago, responses were overwhelmingly negative. Employees liked the appearance of theofficelandscape, butotherwiserated it as noisier, less efficient, and less practical than their old offices. D espitethese reactions, M ontgomery Ward's headquarters was designed as an office landscape (Pile, 1976). At the C elaneseC orporation in $\mathrm{N}$ ew York, employee reactions were generally positive, but they complained of alack of privacy. Celanese did not implement officelandscaping in their new offices (Pile, 1976). Similar reactions were noted in an office landscape study at the IBM World Trade Americas/ Far East Corporation H eadquarters in M t. Pleasant, N.Y., which was designed in close consultation with the Q uickborner Team and included approximately 800 planters and a fulltime gardener to care for the plants (Pile, 1977). Employees were pleased with the flexibility and ease with which workstations could be continually revised and relocated, but noiseand loss of privacy were concerns.

\section{What happened to office landscaping?}

Feedback from theofficelandscape trials was mixed. Proponents cited its attractiveness, flexibility, efficient use of space, improved employee morale and productivity, and lower installation costs (Brill et al., 1972; Jaeger, 1969; Zanardelli, 1969). Critics complained of increased noiseand lessprivacy, which impeded productivity. Thesecontradictory reports, coupled with the lack of quantitativeimprovementsin employee morale, efficiency, or work habits, caused officelandscaping to losesupportamong office planners (H oward, 1972; Pile, $1976,1977)$. In theyearsthat followed, office landscapes began to vary drastically from the original Q uickborner designs. Some remained fully open office landscapes, while others assumed characteristics common to both open and conventional offices (Pile, 1976). In many, plants began to play a secondary role to furniture systems.

The original goals of improved communication, efficiency, and productivity werereplaced asofficelandscaping began to be marketed as new furniture design, specifically, as open planning (H oward, 1972). O pen plan offices did not require that foliage plants be integrated in the design (Boje, 1971). In many cases, thetermsofficelandscaping and open planning appear to have been used interchangeably (Pile, 1976). Studies of some "office landscapes" actually appear to be evaluations of office furniture systems.

Whiletheofficelandscape waspromoted as being quite flexible, many of the components of its physical structure, such as the partitions and planters, were not, in reality, easily moved (Sommer, 1974). The social structure of the organization also was often inflexible, with many high-ranking employees unwilling to accept office landscapephilosophy and reluctant to forfeit their private offices (Sommer, 1974). Even without privateoffices, thepursuit of status continued in the office landscape. Status levels among employees could bereadily determined by theplacement, quality, and quantity of items such as plants and furniture (Pile, 1977; Rodgers, 1968; Sommer, 1974; Zanardelli, 1969). The placement of large foliage plants, in particular, became a significant indicator of status (Snyder, 1995). For example, managers were given clusters of large floor plants for screening their work areas, whereas support staff were provided with smaller tabletop plantsthat provided lessscreening.

\section{Weaknesses in the early evaluations of office landscapes}

$M$ any of the office landscape tests in the 1960 s and 1970 s were case studies relying on anecdotal evidence and self-reported evaluations from employees. Few of them utilized control groups.
Certainly, none of them could be considered double-blind experiments, where neither thesubjectsnor theexperimenters know which is the experimental group and which is the control (Babbie, 1989). M ost importantly, none of them appear to have examined the effects of theplantsalone, without the confounding effects of new furniture, lighting, or equipment.

The influence of being studied, a phenomenon known as the $\mathrm{H}$ awthorne effect, was also a significant consideration in these studies (Babbie, 1989; Pile, 1977; Sommer, 1983). Subjects act differently if they know they are being studied and, in some studies, workers have performed at a higher rate when they knew that they were monitored (Babbie, 1989; Pile, 1977). M any participants of office landscape studies were biased and knew that they were being tested. Responses were also influenced by both employeemoraleand the management's attitudes toward office landscapespriorto theinstallation (Boje, 1971; Pile, 1977). D isgruntled employees tended to react negatively toward office landscaping, while those who enjoyed their jobsweremorelikely to react positively (Pile, 1976).

The ambiguous nature of the concept of productivity and its measurement also made evaluation of employee performance in the office landscape difficult (Boje, 1971; Pile, 1976, 1977; Sommer, 1974). Even the European studies, which appear to have been the catalyst for the American installations, seem to lack concrete data to support claims for increased office productivity (Boje, 1971). There appear to be no studies where worker productivity was monitored before and after the installation of the office landscape, and true control groupswere nonexistent (Boje, 1971). Furthermore, job responsibilitiesand personal work habitsvarygreatly, and employee performance in different work settings is highly individualized (Sommer, 1974).

Despite the limitations of these studies, claims of improved worker productivity in landscaped officesand work areas have persisted since the 1970s (Conklin, 1972, 1978; M archant, 1982; Scrivens, 1980; Snyder, 1995). Apparently, some early proponents believed that the plants, specifically, were responsible for the term office landscape (Duffy, 1969; Rodgers, 1968). Pile (1978) notesthat "thepresence of many plants and the irregularity of patterns 
are, of course, the basis for the term 'Iandscape' - the pattern of parks, woods, or forests rather than those of a grid-iron street layout." I n any case, it is likely that many proponents, believing intuitively that plants are vital to human well-being and hearing the remarkable reports from installations in Germany, attributed the benefits to the plants, thereby encouraging the widespread inclusion of interior plants in office environments in the $U$ nited States.

\section{More recent studies on office landscaping}

Studiesthat arenow appearing have been conducted using valid experimental designs. Some accomplish this by reducing themagnitude of the question to be addressed, focusing on specific, limited aspects of human responses to interiorscapes. For example, some research has focused specifically on the effects of working in the windowless environments typical of many offices. Such studies have shown that peoplein windowless offices appear to use objects found in nature, such as plants, as "window substitutes" (Biner et al., 1993). Someresearchershypothesizethat workers in these settings compensate for a lack of windows by decorating their workspaces with visual materials dominated by nature themes ( $\mathrm{H}$ eerwagen and O rians, 1986; Sommer, 1974). Research examining human productivity in the isolation and confinement of space environments notes that interior decor with visual pattern features common in natural landscapes can reduce the physiological stress caused by mental work (Wise and Rosenberg, 1988). In such environments, pictures of natural viewsserve, to someextent, assubstitutesfor windows (C learwater and C oss, 1991).

Whether people in ordinary work settingsactual ly compensatefor alack of windows by adding plants is unclear. H owever, plants are widely used to personalize and decorate offices, and they are important in improving satisfaction with indoor space (Biner et al., 1993; J ankowski, 1980; Laviana et al., 1983; M ateja, 1988; Shoemaker et al., 1992). Living plants provide visual relief to the stark interiors of many modern offices (Snyder, 1995), and their presence has been shown to have a positive effect on the perceived attitudes projected in a business environment (Aitken and Palmer, 1989).

O ther studies have used experi- mental conditionsto focusmorespecifically on the natural elements that were part of the office landscaping concept. Such studies, for example, have documented that simply viewing plants or outdoor scenes with vegetation can be stress-reducing or can promote positive responses (H oneyman, 1992; Tennessen and Cimprich, 1995; U Irich, 1981; U Irich et al., 1991).

Contemporary research studies using controlled conditions are also documenting the effects of working in indoor environments that contain live plants on people's behavior and attitudes. In recent research in the $U$ nited States, experimental participants were found to be more productive, less stressed, and more attentive while performing a specific computer task in an interiorscaped room than their counterparts in the same room without interior plants (Lohr et al., 1996). Also, in the same environment, dust accumulation was less when interior plants were present, providing improved air quality for the occupants (Lohr and PearsonM ims, 1996).

$\mathrm{N}$ ot all studies confirm such positive impacts from adding plants. Shoemaker et al. (1992) examined theeffects of interiorscaping one floor of an office complex compared to another floor of the office that was decorated with photographs. This study did not find a significant impact from theinterior treatments on workers' self-reported opinions or attitudes toward the work environment. The authors speculated that thenewness of the office complex could have produced a ceiling effect, with all employees feeling so good about the new space, that the questionnaire used in this study may not have been able to detect a positiveresponseto plants, even if it really existed. The authors also noted that low response rates may have contributed to the lack of significance.

Looking for responses to plants under actual working conditions is a difficult undertaking (Sommer, 1983). Experiments designed with sufficient statistical power to document effects under such variable conditions require many subjects or a large treatment effect. Even increasing the number of floorsused in thestudy by Shoemaker et al. (1992) and increasing the questionnaire return rate could have resulted in insufficient observationsto measure differences in this type of study. The experimental protocol used in the Shoemaker study is a good model for this type of research under actual working conditions, but it also demonstratesthe difficulties involved in such an undertaking. A recent experiment in Europe used a similar experimental design; with more people completing the study, the authors were able to document that health complaints, such as coughing and itchyskin, werereduced when plants were added to an office environment (Fjeld et al., 1998).

Larsen et al. (1998) analyzed the effects of interior plants on participants' productivity, attitudes toward a workspace, and overall mood in an officeenvironment under controlled conditions. Their resultsfound significantly improved qualitative effects, including self-reported mood, perceived office attractiveness, and perceived comfort when plants were present than when they were not present; however, the actual performance on a productivity task decreased when the number of plantsadded to theworkspaceincreased. Theauthorsspeculated that theremight have been too many plants, increasing the subject's distraction from the productivity task. They also noted that their productivity task, crossing out specific letters in a sample of type, did not require much mental effort. The task was only followed for $3 \mathrm{~min}$, which the authors note is probably too short a time frame for mental fatigue to develop. Thisexperiment, also using good protocol, demonstrates some of the difficulties that can occur when testing the effects of productivity under artificial conditions.

$M$ ore research is needed to expand and clarify the effects of plantsin offices. Research under both actual working conditions and controlled conditions will be needed before we can fully understand the impacts of using plants in the work environment.

\section{Conclusions}

Interior plants undoubtedly have been, and continue to be, an important component of the American office environment. Research is beginning to scientifically document the benefits of interior plantingsto human comfort, wellbeing, and productivity (Fjeld et al., 1998; Lohr et al., 1996; Shoemaker et al., 1992), but this research area clearly requires more study. If researchers can continue to provide concrete evidence that interaction with plants is directly linked to improved human health and well-being, this information could pro- 
vide further justification for the use of interior plants in a variety of indoor work settings (Lohr, 1995; Lohr and Relf, 1993). Asaresult, all aspects of the interior plant industry, including production, sales, design, and maintenance, will have the potential to expand their markets (Brown, 1990; Relf, 1990). U Itimately, theimproved working environment created by interiorscaping will contributeto an enhanced quality of life for employees.

\section{Literature cited}

Aitken, J.E. and R.D. Palmer. 1989. The use of plantsto promotewarmth and caring in a business environment. Amer. Culture Assn. 11th Annu. M tg., St. Louis.

Babbie, E. 1989. The practice of social research. Wadsworth, Belmont, Calif.

Biner, P.M., D.L. Butler, T.E. Lovegrove, and R.L. Burns. 1993. Windowlessness in the workplace: A reexamination of the compensation hypothesis. Environ. Behavior 25:205-227.

Boje, A. 1971. Open-plan offices. Business Books, London.

B rill, M., T. Collison, and E. H arvard. 1972. The management of changeand productive interiors. H auserman, Buffalo, N.Y.

Brown, R. 1990. Better business through science. Interior L andscape Ind. 7(7):3239.

Clearwater, Y.A. and R.G. Coss. 1991. Functional esthetics to enhance well-being in isolated and confined settings, p. 331-348. In: A.A. H arrison, Y.A. Clearwater, and C.P. M cKay (eds.). From Antarcticato outer space: Life in isolation and confinement. Springer-V erlag, N ew York.

Conklin, E. 1972. M an and plants-A primal association. Amer. N urseryman 136(9):42, 46-49.

Conklin, E. 1978. Interior landscaping. J. Arboricult. 4:73-79.

D uffy, F. 1969. O ffice landscaping: A new approach to office planning. Anbar Publ., London.

Fisher, K. 1990. People love plants, plants heal people. Amer. H ort. 10:11-15.

Fjeld, T., B. Veiersted, L. Sandvik, G. Riise, and F. Levy. 1998. The effect of indoor foliageplantson health and discomfort symptoms among office workers. Indoor Built Environ. 7:204-209.

H eerwagen, J.H . and G.H . O rians. 1986. Adaptations to windowlessness: A study of the use of visual decor in windowed and windowless offices. Environ. Behavior 18:623-639.
H oneyman, M.K. 1992. Vegetation and stress: A comparison study of varying amounts of vegetation in countryside and urban scenes, p. 117-119. In: D. Relf (ed.). The role of horticulture in human wellbeing and social development: A national symposium. Timber Press, Portland, O re.

H oward, P. 1972. O ffice landscaping revisited. D esign Environ. 3(3):41-46.

J aeger, D . 1969. O ffice landscape-A systems concept, p. 10-33. In: M anagement conference. I mproving office environment. Business Press, Elmhurst, III.

J ankowski, W. 1980. Light and airy underground. Lighting Design Appl. (Jan.):1418.

Larsen, L., J. Adams, B. D eal, B. Kweon, and E. Tyler. 1998. Plants in the workplace: The effects of plant density on productivity, attitudes, and perceptions. Environ. Behavior 30:61-281.

Laviana, J.E., R.H. Mattson, and F.H. Rohles. 1983. Plants as enhancers of the indoor environment, p. 738-741. In: A.T. Pope and L.D. H augh (eds.). Proc. H uman Factors Soc. 27th Annu. M tg. H uman Factors Soc., Santa M onica, Calif.

Lewis, C.A. 1979. Healing in the urban environment: A person/ plant viewpoint. J. Amer. Planning Assn. 45:330-338.

Lewis, C.A. 1996. Green nature/ human nature: The meaning of plants in our lives. U niv. I llinois Press, U rbana, III.

Lohr, V.I. 1995. Environmental horticulture industry representatives rank research on the impacts of plants on human health as important. H ortT echnology 5:350.

Lohr, V.I. and C.H. Pearson-M ims. 1996. Particulate matter accumulation on horizontal surfaces in interiors: Influence of foliage plants. Atmos. Environ. 30:25652568.

Lohr, V.I., C.H . Pearson-M ims, and G.K. Goodwin. 1996. Interior plants may improve worker productivity and reducestress in a windowless environment. J. Environ. H ort. 14:97-100.

Lohr, V.I and D. Relf. 1993. H uman issues in horticulture: Research priorities. HortTechnology 3:106-107.

$M$ archant, B. 1982. A look at theindustryDimensions and prospects. Amer. N urseryman 156(10):30-49.

M ateja, D . 1988. E mployee perceptions of plants in the office: A study of J ohn Deere Co. H eadquarters, M oline, IL. In: D. Lawrence, R. H abe, A. Hacker, and D. Sherrod (eds.). People'sneeds/ planet management: Paths to co-existence: Proc. 19th Annu. Conf. Environ. Design Res. Assn. EDRA, Wash., D.C.
Pile, J. 1976. Interiors 3rd book of offices. Whitney Library of D esign, N ew York.

Pile, J. 1977. Theopen office: D oesit work? Prog. Architect. 6:68-81.

Pile, J. 1978. O pen officeplanning: A handbook for interior designers and architects. Whitney Library of D esign, N ew York.

Relf, P.D. 1990. Psychological and sociological response to plants: Implications for horticulture. H ortScience 25:11-13.

Rodgers, S.G. 1968. M odularityversusfreeform clustering, p. 8-32. In: BusinessE quipment $M$ anufacturers Assn. $N$ ew conceptsin office design. Business Press, Elmhurst, III.

Scrivens, S. 1980. Interior planting in large buildings. Architect. Press, London.

Shoemaker, C.A., K. Randall, P.D. Relf, and E.S. Geller. 1992. Relationships between plants, behavior, and attitudes in an office environment. H ortTechnology 2:205-206.

Snyder, S.D. 1995. Environmental interiorscapes: A designer'sguideto interior plantscaping and automated irrigation systems. WhitneyL ibrary of D esign, N ew York.

Sommer, R. 1974. Tight spaces: $\mathrm{H}$ ard architectureand how to humanizeit. Prentice$\mathrm{H}$ all, Englewood Cliffs, N.J .

Sommer, R. 1983. C reating buildings with people in mind. Prentice-H all, Englewood Cliffs, N.J.

Sundstrom, E. 1986. Work places: The psychology of the physical environment in officesand factories. CambridgeU niv. Press, $\mathrm{N}$ ew York.

Tennessen, C.M . and B. Cimprich. 1995. Views to nature: Effects on attention. J. Environ. Psychol. 15:77-85.

Tresch, P.S. 1971. About our cover. H ortScience 6:118.

U Irich, R.S. 1981. Natural versus urban scenes: Some psychophysiological effects. Environ. Behavior 13:523-556.

U Irich, R.S., R.F. Simons, B.D. Losito, E. Fiorito, M .A. M iles, and M. Zelson. 1991. Stress recovery during exposure to natural and urban environments. J. Environ. Psychology 11:201-230.

Wise, J.A. and E. Rosenberg. 1988. The effects of interior treatmentson performance stress in three types of mental tasks. Ctr. Integrated Facilities Res., Tech. Rpt. Ser. N o. 002-02-1988. F.E. Seidman School of Business, Grand Valley State Univ., Allendale, Mich.

Zanardelli, H. 1969. Life in a landscape office, p. 34-42. In: M anagement Conference. Improving office environment. Business Press, Elmhurst, III. 